\title{
Optimalisasi Pemanfaatan Ekstrak Daun Siamih (Ageratum conyzoides L) sebagai Antioksidan pada Tubuh Manusia Menggunakan Metode DPPH
}

\section{Optimization of the Utilization of Siamih Leaf Extract (Ageratum conyzoides L) as an Antioxidant in the Human Body using the DPPH Method}

\section{Lovera Anggraini $^{*}$, Deri Islami ${ }^{1}$}

${ }^{1}$ Department of Pharmaceutical and Food Analysts, Faculty Medicine and health Sciences of Abdurrab University, Pekanbaru, 28291, Indonesia.

\begin{abstract}
A B S T R A K
Senyawa antioksidan semakin banyak digunakan dalam bidang pangan ataupun bidang kesehatan. Riset ini bertujuan buat mengenali manfaat ekstrak daun siamih (Ageratum conyzoides L) selaku antioksidan pada badan manusia, dengan memakai pengujian fitokimia buat mengenali senyawa metabolit sekunder yang tercantum dalam ekstrak daun Siamih (Ageratum conyzoides L), dan memastikan besarnya aktifitas antioksidan senyawa metabolit sekunder yang dihasilkan oleh ekstrak daun siamih (Ageratum conyzoides L) menggunakan prosedur DPPH. Perlengkapan yang digunakan yakni microplate reader dengan panjang gelombang maksimum pengukuran merupakan $520 \mathrm{~nm}$. Parameter yang digunakan untuk mengenali aktifitas antioksidan yakni( Inhibition Concentration). Berdasarkan riset ini, ilustrasi ekstrak metanol daun siamih (Ageratum conyzoides L) mempunyai nilai lebih besar dibanding sampel ekstrak n- heksan daun siamih (Ageratum conyzoides L).
\end{abstract}

\section{$A B S T R A C T$}

Antioxidant compounds are increasingly used in the field of food or the medical field. This research aims to create recognize the benefits of the leaf extract siamih (Ageratum conyzoides L) as an antioxidant in the human body using testing phytochemicals for recognizing secondary metabolites contained in the leaf extract siamih (Ageratum conyzoides L) and make sure the amount of antioxidant activity of secondary metabolites which produced by leaf extract siamih (Ageratum conyzoides L) using DPPH procedure. Supplies used the microplate reader with maximum wavelength is $520 \mathrm{~nm}$ measurements. The parameters used to identify the antioxidant activity (Inhibition Concentration). This research illustrates siamih leaf methanol extract (Ageratum conyzoides L) has a greater value than the $n$-hexane extracts of leaf samples siamih (Ageratum conyzoides L).

Kata kunci/Keyword : antioksidan; siamih; DPPH; antioxidants.

I N F O A R T I K E L

Received: 06 Oct 2020;

Revised: 15 Nov 2020;

* coresponding author: lovera.anggraini@univrab.ac.id

Accepted: 20 Nov 2020 


\section{PENDAHULUAN}

Radikal bebas merupakan sesuatu senyawa ataupun molekul yang mempunyai satu ataupun lebih elektron yang tidak memiliki pasangan sehingga menyebabkan senyawa akan sangat reaktif untuk mencari pasangan, dengan cara melakukan pengikatan pada elektron molekul yang terletak di sekitarnya. Pada umumnya radikal bebas dapat bersumber dari dalam tubuh dari hasil proses metabolisme atau dapat juga berasal dari lingkungan atau dari luar tubuh. Radikal bebas yang bersumber dari lingkungan atau dari luar tubuh dapat diakibatkan oleh berbagai aspek, seperti asap rokok, kontaminasi pestisida pada makanan, pencemaran udara dan radiasi (Mbaoji et al., 2016). Senyawa antioksidan merupakan senyawa yang populer digunakan baik dalam bidang pangan maupun bidang kesehatan. Dalam bidang pangan, antioksidan dapat berfungsi sebagai bahan pengawet alami. Sedangkan bidang kesehatan kandungan senyawa antioksidan dapat berfungsi sebagai pencegahan berbagai penyakit kronis. Pemanfaatan senyawa antioksidan telah dibuktikan secara ilmiah dapat mengurangi efek penyakit kronis, seperti jantung koroner dan kanker.

Senyawa Antioksidan yang sering digunakan sebagai pencegah penyakit menahun seperti kanker serta jantung koroner pada umumnya merupakan antioksidan yang bersumber dari bahan kimia. Namun, seperti yang kita ketahui bahwa, bahan kimia yang digunakan seringkali memiliki dampak negatif untuk kesehatan (Purwanto, Bahri, \& Ridhay, 2017). Akhir-akhir ini peneliti banyak tertarik pada pemanfaatan bahan alam sebagai antioksidan, untuk mengurangi penggunaan bahan kimia. Selain memiliki efek samping, antioksidan yang dibuat dari bahan kimia, juga lebih mahal sehingga tidak bernilai ekonomis (Pangestu, Nurhamidah, \& Elvinawati, 2017). Oleh karena itu pemanfaatan bahan alam menjadi hal yang menarik untuk dijadikan sebagai dasar pembuatan antioksidan, seperti halnya pemanfaatan ekstrak daun Siamih (Ageratum conyzoides L.) yang bisa dikatakan belum dijumpai sebagai antioksidan alami untuk kesehatan pada manusia.

Senyawa antioksidan dapat digunakan untuk menetralisir radikal bebas (Mariani, Rahman, \& Supriadi, 2018). Pada saat antioksidan mengikat radikal bebas dengan cara menerima maupun menyumbangkan elektron, aakn menyebabkan radikal bebas menjadi lebih stabil sehingga tidak berbahaya bagi kesehatan. Senyawa antioksidan alami banyak ditemukan pada sayur, buah dan tumbuhan obat (Zerargui, Baghiani, Khennouf, \& Arrar, 2016).

Pemanfaatan bahan alami selaku obat tradisional hendaknya tidak hanya bersumber pada pengalaman yang telah diwariskan atau diberikan oleh masyarakat secara turuntemurun, namun perlu adanya pembuktian secara ilmiah.

Berbagai tanaman obat sudah dikenal memiliki senyawa aktif yang bisa efektif untuk pengobatan penyakit. Bermacam riset sudah dicoba untuk melihat aktivitas farmakologi serta kandungan kimia bahan alam. Salah satu bahan alam yang sudah dilaporkan mempunyai aktivitas farmakologi yaitu siamih (Ageratum conyzoides L).

Banyaknya tumbuhan yang memiliki kandungan obat menggambarkan sumber energi hayati yang sangat besar untuk dijadikan sebagai bahan baku obat herbal (Hermansyah \& Mucrito, 2017) dimana terdapat ribuan spesies tanaman yang sudah dimanfaatkan sebagai alternatif bahan baku obat (Amir, Murcitro, Shamsudin, \& Kassim, 2017). Dapat dimanfaatkannya tumbuhan obat dikarenakan terdapatnya kandungan metabolit sekunder dengan bermacam struktur molekul serta tingkatan aktivitas biologis sehingga bisa mengurangi serta menyembuhkan bermacam penyakit (Hermansyah \& Mucrito, 2017; Yati, Sumpono, \& Candra, 2018). Sebagai contoh tumbuhan daun siamih (Ageratum conyzoides L).

Pada penelitian ini dilakukan ekstrak daun siamih (Ageratum conyzoides L) sebagai antioksidan pada tubuh manusia, 
dengan menggunakan pengujian fitokimia untuk mengenali senyawa metabolit sekunder yang terdapat di dalam ekstrak daun siamih, dan memastikan besarnya aktivitas antioksidan yang telah dihasilkan dari senyawa metabolit sekunder yang ada dalam daun siamih menggunakan metode DPPH.

\section{METODE PENELITIAN}

\section{Pengambilan Daun Siamih (Ageratum conyzoides $\mathrm{L}$ )}

Daun siamih diambil di daerah sekitaran hutan Rumbai Pekanbaru.

\section{Pembuatan ekstrak daun Siamih (Ageratum conyzoides L)}

Daun siamih (Ageratum conyzoides L) fresh dikering-anginkan kemudian dihaluskan. Setelah itu ditimbang 400 gram kemudian diekstrak dengan menggunakan $2000 \mathrm{~mL}$ metanol selama 3 hari dengan ulangan sebanyak 3 kali. Ekstrak disaring serta diuapkan pelarutnya dengan menggunakan rotary evaporator. Ekstrak pekat diperoleh sekitar 5 gram, kemudian diletakkan di beaker gelas ukuran $100 \mathrm{~mL}$ untuk dibuat larutan penghambat dengan konsentrasi yang berbeda yakni $1 \mathrm{~g} / \mathrm{L}, 2 \mathrm{~g} / \mathrm{L}$, $4 \mathrm{~g} / \mathrm{L}, 6 \mathrm{~g} / \mathrm{L}$, serta $8 \mathrm{~g} / \mathrm{L}$.

\section{Uji fitokimia daun Siamih (Ageratum conyzoides $\mathrm{L}$ )}

Tata cara pengecekan kandungan senyawa flavonoid, triterpenoid, steroid, fenolik, ialah: 1 gram sampel fresh dimasukkan ke dalam tabung reaksi, selanjutnya dimaserasi menggunakan pelarut metanol yang sudah dipanaskan (di atas penangas air) selama 15 menit. Setelah itu disaring dan dimasukkan ke dalam tabung reaksi lain serta dibiarkan larutan metanol menguap sampai kering. Kemudian ditambahkan kloroform dan air dengan perbandingan 1:1 setiap $5 \mathrm{~mL}$, kocok secara baik, setelah itu masukkan dalam tabung reaksi, biarkan sejenak sampai terbentuk 2 susunan kloroform- air. Susunan kloroform di bagian dasar digunakan buat pengecekan senyawa triterpenoid serta steroid. Sebaliknya susunan air digunakan buat pengecekan senyawa fenolik serta flavonoid.

\section{Pengecekan Flavonoid}

Sebagian dari larutan air diambil serta dipindahkan dengan memakai pipet tetes ke dalam tabung respon, dan ditambahkan asam klorida pekat serta sebagian butir bubuk magnesium, terjadinya corak oranye hingga merah menampilkan terdapatnya flavonoid

\section{Pengecekan Fenolik}

Sebagian dari larutan air diambil serta dipindahkan dengan menggunakan pipet tetes ke dalam tabung respon kecil, setelah itu tambahkan $\mathrm{FeCl}_{3}$ tercipta corak biru menunjukkan terdapatnya senyawa fenolik.

\section{Pengecekan Triterpenoid serta Steroid}

Lapisan kloroform yang ada diambil sedikit serta dimasukkan ke dalam 3 lubang pelat tetes dan didiamkan sampai kering, ke dalam satu lubang pelat tetes ditambahkan setetes anhidrida asetat serta setetes $\mathrm{H}_{2} \mathrm{SO}_{4}$ pekat. Terjadinya corak hijau ataupun biru menunjukkan terdapatnya steroid. Sebaliknya terjadinya corak merah menunjukkan terdapatnya triterpenoid.

\section{Pengecekan Alkaloid}

Sampel sebanyak 2-4 gram dipotong kecil, setelah itu dihaluskan pada lumpang dengan akumulasi sedikit pasir serta $10 \mathrm{~mL}$ kloroform-amoniak $0,05 \mathrm{~N}$, setelah itu diaduk ataupun digerus sampai halus. Larutan disaring dengan corong ukuran kecil, di dalamnya harus diletakkan kapas selaku penyaring serta hasil saringan dimasukkan ke dalam suatu tabung reaksi, setelah itu tambahkan 10 tetes $\mathrm{H}_{2} \mathrm{SO}_{4} 2 \mathrm{~N}$ serta kocok secara lama-lama. Biarkan sejenak hingga tercipta pemisahan susunan asam serta kloroform. Susunan asam diambil dengan dorongan pipet serta dipindahkan ke dalam suatu tabung. Setelah itu tambahkan pereaksi 
Meyer, reaksi positif ditandai dengan terdapatnya endapan putih.

\section{Uji Aktivitas Antioksidan}

Uji aktivitas antioksidan dicobakan dengan memanfaatkan mikroplate reader two fold delution dengan metoda DPPH (1, 1diphenyl-2- picryl hydrazyl) pada panjang gelombang $520 \mathrm{~nm}$. Sampel sebanyak 2 miligram dalam $2 \mathrm{~mL} \mathrm{MeOH}$ dalam perihal ini konsentrasi ilustrasi 1000 miligram/ mL. Baris A dilakukan pemasukkan sampel sebanyak $100 \mu \mathrm{L}$ (plate terdiri dari baris A- H tiap- tiap berjumlah 12 lubang). Sebanyak $50 \mu \mathrm{L} \mathrm{MeOH}$ dimasukkan pada tiap- tiap lubang pada baris B-F. Baris A dipipet sebanyak $50 \mu \mathrm{L}$ serta dimasukkan ke baris $\mathrm{B}$, baris $\mathrm{B}$ dipipet $50 \mu \mathrm{L}$ dimasukkan ke baris $\mathrm{C}$ serta dicoba hingga baris $F$, baris $F$ dipipet $50 \mu \mathrm{L}$ kemudian dibuang, sehingga didapatkan konsentrasi 1000 miligram $/ \mathrm{mL}$, 500 miligram $/ \mathrm{mL}, 250$ miligram/ mL, 125 miligram $/ \mathrm{mL}, 62,5$ miligram $/ \mathrm{mL}$ serta 31,25 miligram/ mL. Sebaliknya pada baris G- H diisi dengan $\mathrm{MeOH} 50 \mu \mathrm{L}$, spesial pada baris $\mathrm{H}$ diisi cuma lubang 1- 6 .

Baris A-G ditambahkan DPPH sebanyak $80 \mu \mathrm{L}$ dengan konsentrasi 40 miligram/ $\mathrm{mL}$, setelah itu diinkubasi selama 30 menit. Radikal bebas diukur melalui penyusutan absorbansi DPPH dengan microplate reader serta olah informasi. Kontrol positif yang digunakan sebagai pembanding ialah vit $\mathrm{C}$ dengan konsentrasi 50 miligram $/ \mathrm{mL}$. Nilai \% inhibisi dihitung dengan rumus sebagai berikut:

$$
\% \text { Hambatan }=\frac{\left(A_{\text {kontrol }}-A_{\text {sampel }}\right)}{A_{\text {kontrol }}} \times 100
$$

Keterangan:

$$
\begin{aligned}
\mathrm{A}_{\text {kontrol }}= & \begin{array}{l}
\text { Absorbansi tidak mengandung } \\
\text { sampel }
\end{array} \\
\mathrm{A}_{\text {sampel }}= & \text { Absorbansi sampel }
\end{aligned}
$$

\section{HASIL DAN PEMBAHASAN}

Uji Fitokimia dari Ekstrak Daun Siamih (Ageratum conyzoides $\mathrm{L}$ )

Tabel 1. Hasil uji fitokimia

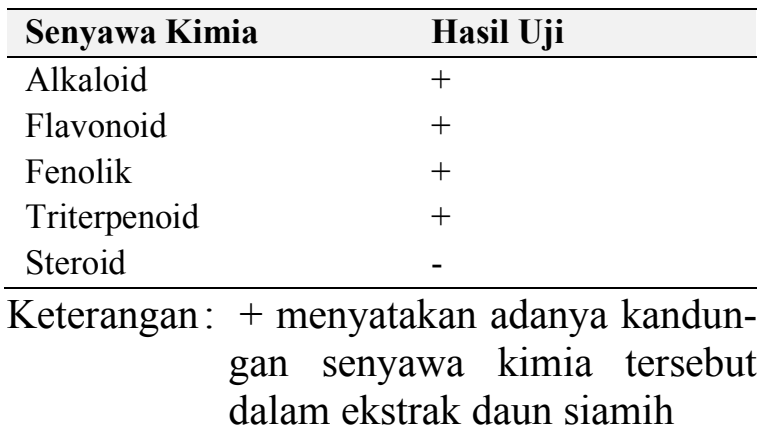

Uji fitokimia dilakukan untuk mengetahui ada atau tidaknya senyawa tersebut dalam ekstrak daun siamih. Tabel 1 menunjukkan bahwa ekstrak daun siamih (Ageratum conyzoides L) mengandung alkaloid, flavonoid, fenolik, dan triterpenoid. Itu terbukti dengan adanya tanda $(+)$ pada Tabel 1.

\section{Uji Aktivitas Antioksidan dari Ekstrak daun siamih (Ageratum conyzoides L)}

Aktivitas antioksidan pada ekstrak daun siamih yang di uji dengan memakai prosedur DPPH dengan spektrofotometri UV- Vis dengan panjang gelombang maksimum $517 \mathrm{~nm}$. Besarnya aktivitas antioksidan ditunjukkan dengan nilai $\mathrm{IC}_{50}$, ialah konsentrasi larutan ilustrasi yang diperlukan buat membatasi $50 \%$ radikal leluasa DPPH (Purwanto et al., 2017). Nilai $\mathrm{IC}_{50}$ pada masing-masing ekstrak dengan pelarut n-heksan, serta metanol ditetapkan dengan memakai persamaan regresi linier dari kurva ikatan konsentrasi ilustrasi terhadap persen inhibisi dengan persamaan $\mathrm{Y}=\mathrm{ax}+\mathrm{b}$, konsentrasi ilustrasi (ppm) bagaikan sumbu (X) serta nilai persentase inhibisi bagaikan sumbu (Y) (Yati et al., 2018). Bersumber pada persamaan regresi linier dari Gambar 1, serta Gambar 2, ikatan antara konsentrasi hasil ekstrak terhadap persentase inhibisi, diperoleh nilai $\mathrm{IC}_{50}$ 
berturut- turut ialah 1133,8964 ppm, 708,8541 ppm.

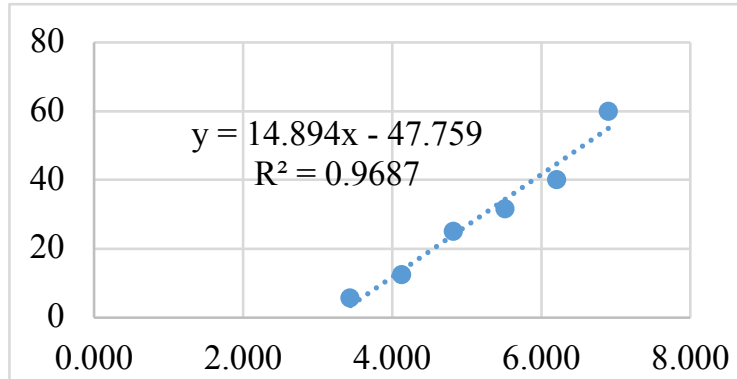

Gambar 1. Grafik persamaan regresi aktivitas antioksidan dengan pelarut n-heksan

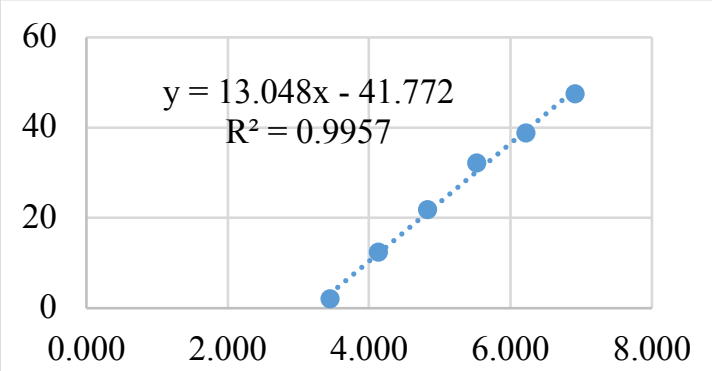

Gambar 2. Grafik persamaan regresi aktivitas antioksidan dengan pelarut Metanol

Perbandingan tipe pelarut yang telah digunakan pada proses ekstraksi pengaruhi aktivitas antioksidan yang didapat. Bersumber pada pada uji kegiatan antioksidan menampilkan kalau pemakaian pelarut metanol membagikan nilai $\mathrm{IC}_{50}$ terkecil (kegiatan paling tinggi) dibanding pada pemakaian pelarut n-heksan (BrandWilliams, Cuvelier, \& Berset, 1995; Purwanto et al., 2017). Perihal ini diprediksi sebab di dalam ilustrasi daun siamih terdapat banyak senyawa bioaktif bertabiat polar bila dibanding senyawa bioaktif bertabiat non polar serta semipolar. Sehingga menyebabkan pelarut polar (metanol) lebih banyak mengikat senyawa bioaktif yang terdapat pada daun siamih (Purwanto et al., 2017). Antioksidan sangat kokoh apabila mempunyai nilai IC50 kurang dari 50 ppm, antioksidan kokoh mempunyai nilai $\mathrm{IC}_{50}$ terletak pada kisaran 50 ppm sampai 100 ppm, antioksidan lagi mempunyai nilai $\mathrm{IC}_{50}$ berada antara $100 \mathrm{ppm}$ sampai $150 \mathrm{ppm}$, antioksidan lemah mempunyai kisaran 150 ppm sampai 200 ppm serta nilai $\mathrm{IC}_{50}$ lebih dari $200 \mathrm{ppm}$ ialah antioksidan berifat sangat lemah (Mariani et al., 2018; Yati et al., 2018). Secara khusus, sesuatu senyawa dikatakan mempunyai aktifitas antioksidan sangat kokoh apabila $\mathrm{IC}_{50} ; 50 \mathrm{ppm}$, kokoh apabila $\mathrm{IC}_{50}$ bernilai $50-100 \mathrm{ppm}$, lagi apabila $\mathrm{IC}_{50}$ bernilai 101-250, serta lemah apabila $\mathrm{IC}_{50}$ 251- 500 ppm (Sarfina, Nurhamidah, \& Handayani, 2017; Widyawati, 2016).

Berdasarkan hasil pengamatan yang diperoleh menunjukkan bahwa seluruh ekstrak daun siamih (Ageratum conyzoides L) mempunyai aktivitas antioksidan lebih baik dengan menggunakan pelarut yang bersifat polar dibandingkan dengan pelarut yang bersifat non polar. Perbedaan aktivitas yang diperoleh dari ekstrak daun siamih (Ageratum conyzoides L) tersebut kemungkinan diakibatkan terdapatnya perbedaan kandungan serta jumlah senyawa aktif yang terdapat dalam ekstrak, sehingga aktivitas antioksidan yang diperoleh berbeda (Winarsi, 2007). Ekstrak dengan pelarut metanol memiliki antioksidan yang lebih besar dibanding dengan ekstrak dengan pelarut n-heksan, hal ini kemunkinan disebabkan karena senyawa aktif antioksidan lebih banyak yang bersifat polar dibandingkan dengan senyawa aktif anti oksidan yang bersifat non polar (Mariani et al., 2018).

\section{KESIMPULAN}

Berdasarkan hasil penelitian yang diperoleh, ekstrak daun siamih (Ageratum conyzoides L) mengandung alkaloid, flavonoid, fenolik, dan triterpenoid. Hasil ekstrak pada persentase inhibisi, diperoleh nilai $\mathrm{IC}_{50}$ berturut- turut ialah 1133,8964 ppm, 708,8541 ppm. Hasil ekstrak metanol daun siamih (Ageratum conyzoides L) mempunyai nilai lebih besar dibanding sampel ekstrak n-heksan daun siamih (Ageratum conyzoides L). Hal tersebut menunjukkan bahwa ekstrak daun siamih mempunyai aktivitas antioksidan lebih baik pada pelarut yang bersifat polar daripada non polar. 


\section{DAFTAR RUJUKAN}

Amir, H., Murcitro, B. G., Shamsudin, A., \& Kassim, M. N. I. (2017). The potential use of Phaleria macrocarpa leaves extract as an alternative drug for breast cancer among women living in poverty. Asian Journal For Poverty Studies (AJPS), 3(2).

Brand-Williams, W., Cuvelier, M. E., \& Berset, C. (1995). Use of a free radical method to evaluate antioxidant activity. LWT - Food Science and Technology, 28(1), 25-30. https://doi.org/ 10.1016/S0023-6438(95)80008-5

Hermansyah, A., \& Mucrito, B. G. (2017). Uji microtetrazolium (MTT) ekstrak metanol daun Phaleria macrocarpa (Scheff.) Boerl terhadap sel kaker payudara MCF-7. Alotrop, 1(1).

Mariani, S., Rahman, N., \& Supriadi, S. (2018). Uji Aktivitas Antioksidan Ekstrak Buah Semangka (Citrullus lanatus). Jurnal Akademika Kimia, 7, 107. https://doi.org/10.22487/j247 75185.2018.v7.i3.11905

Mbaoji, F., Ezike, A., Nworu, C., Onyeto, C., Nwabunike, I., OKOLI, I., \& Akah, P. (2016). Antioxidant and hepatoprotective potentials of Stemonocoleus micranthus harms (Fabaceae) stem bark extract. International Journal of Pharmacy and Pharmaceutical Sciences, 8, 47-51.

Pangestu, N. S., Nurhamidah, \& Elvinawati. (2017). Aktivitas antioksidan dan entibakteri ekstrak daun Jatropha gossypifolia L. Alotrop, 1(1).
Purwanto, D., Bahri, S., \& Ridhay, A. (2017). Uji aktivitas antioksidan ekstrak buah Purnajiwa (Kopsia arborea blume.) dengan berbagai pelarut. Kovalen, 3(1), 24-32. https://doi.org/ 10.22487/j24775398.2017.v3.i1.8230

Sarfina, J., Nurhamidah, \& Handayani, D. (2017). Uji aktivitas antioksidan dan antibakteri ekstrak daun Ricinus communis L (jarak kepyar). Alotrop, 1(1).

Widyawati, P. S. (2016). Determination of antioxidant capacity in Pluchea indica less leaves extract and its fractions. International Journal of Pharmacy and Pharmaceutical Sciences, 8, 32. https://doi.org/10.22159/ijpps.2016v8i9 .11410

Winarsi, H. (2007). Antioksidan alami dan radikal bebas. Yogyakarta: Kanisius.

Yati, S. J., Sumpono, \& Candra, I. N. (2018). Potensi aktivitas antioksidan metabolit sekunder dari bakteri endofit pada daun Moringa oleifera L. Alotrop, 2(1).

Zerargui, F., Baghiani, A., Khennouf, S., \& Arrar, L. (2016). Antioxidant activity assessment of Tamus communis L. Roots. International Journal of Pharmacy and Pharmaceutical Sciences, 8, 64-71. https://doi.org/ 10.22159/ijpps.2016v8i12.14327 